national scholarship, and after completing the course there went to Trinity College, Cambridge, in 1891 with a major scholarship. He obtained a first in Part 1 of the Natural Science Tripos in 1892 and in Part 2 he had the rare distinction for those days of obtaining a double first, in physics and chemistry. Afterwards he was appointed Coutts-Trotter Student and worked in the Cavendish Laboratory under Sir J. J. Thomson until 1896.

Upon leaving Cambridge, Smith returned to the Royal College of Science, London, as senior demonstrator in physics and became assistant professor in 1912. He obtained the D.Sc. degree of London in 1908 and was elected a fellow of the Royal Society in 1914. During this period at South Kensington, he took a prominent part in the work of the Physical Society of London, being honorary secretary from 1908 until 1916 and vice-president during 1916-19. In addition to his heavy secretarial and teaching work, he did a great deal of research in this phase of his career and it was probably his most fruitful period.

In 1919 he succeeded Poynting as professor of physics at Birmingham and undertook the difficult task of coping with the many problems arising from the First World War, particularly those resulting from a great increase in the number of students. Somewhat later, about 1924, he organised a new honours course in physics, as up to that time only a general degree had been awarded. He was dean of the Faculty of Science from 1929 until 1932. In 1936 he retired and was appointed emeritus professor, and from that time until his death he lived a quiet and somewhat secluded life.

In his researches, Smith devoted himself almost exclusively to two fields of work. His first investigation arose quite naturally from his training in both physics and chemistry; he selected it himself and worked at it in the Cavendish with very little guidance. It dealt with the contact difference of potential arising at a mercury - electrolyte interface, and necessitated a great deal of careful observation using various types of capillary electrometer; the conclusions were published in the Phil.Trans. Roy. Soc. of 1899. Later, at South Kensington, with the assistance of collaborators, he extended and amplified this work, turning to problems of electrolytic resistance and ionic migration. The results of these experiments were published in a series of papers in the Phil. Mag. and the Proceedings of the Physical Society.

The second and perhaps the more important field of Smith's work started from a problem in ferromagnetism suggested to him at South Kensington by Sir Arthur Rücker, who surmised that an exam. ination of the magnetic properties of meteoric iron might throw some light upon the cause of terrestrial magnetism. It soon became clear, however, that this was no problem in terrestrial magnetism but rather a problem from the domain common to geology, metallurgy and physics. The meteoric irons are, in fact, examples of iron-nickel alloys which have cooled with extraordinary slowness and show structural characteristics not reproducible by artificial means. Smith worked alone on this question for a number of years, using a method of investigation simple in principle but requiring great skill and care in execution. He published the results of his observa. tions in an important memoir appearing in the Phil. Trans. Roy. Soc. for 1908.

This work was continued at Birmingham where, in addition to extensions of the magnetic technique, metallographic and X-ray methods were called into service. During these years a great deal of assistance was given by the late James Young, who published a number of papers dealing with the results of the $\mathrm{X}$-ray examination of some of these meteoric specimens. The magnetic and metallographic work was carried out under Smith's direction, and there exists a great deal of unpublished material. It is probable that towards the end of his life Smith was searching for some far-reaching synthesis of the observations which he failed to discover. In March 1939 he pub. lished in Nature a very brief summary of the work and of his tentative conclusions.

Smith was a man of great personal charm with a manner at once disarming and dignified. Over many younger men he exercised a special fascination, arising from a genuine gift of sympathy and also from the interest of his conversation. As a teacher he was held in the highest esteem throughout his life. In 1900 he married Dorothy Muriel Stamp who, together with an only daughter, survives him.

M. L. Oliphant

A. A. DEE

\section{King Ferdinand of Bulgaria}

Ex-King Ferdinand of Bulgaria, who died recently at Coburg at the age of eighty-seven, was born a prince of Saxe-Coburg Gotha. From early youth he had a passion for natural history; but he was no mere amateur, and his studies of botany, entomology and ornithology were serious and scientific. Of the three, his chief interest lay in ornithology, and he first made his appearance among ornithologists at the age of thirteen, under the guidance of Crown Prince Rudolf of Austria, himself an ornithologist of repute. In 1887 Prince Ferdinand joined the Deutsche Ornithologische Gesellschaft, of which Society he remained patron until his death; in later years he was elected an honorary member of the Royal Hungarian Institute of Ornithology and also of the British Ornithologists' Union. In 1879 he made an official visit to Brazil the opportunity for studying the bird-life of South America, and on becoming Tsar of Bulgaria he gave every encouragement to the study of the ornithology of the Balkans and the collection of specimens. The museums and zoological gardens of Sofia are further and concrete evidence of his active interest.

After his abdication, he retired to Coburg, where he devoted most of his time to his private museum and large collection of living birds, though he frequently visited his castle in the Carpathians. The aviaries at Coburg contained more than eight hundred specimens, including many rare species, most of which had been collected by King Ferdinand himself, and he knew where each one had been obtained or purchased. He would spend hours in his aviaries studying the habits of the birds. A section of the gardens was set aside for wild-flowers which the King had either collected himself or had had given to him, from every part of the world ; and, as with the birds, he knew the history of each plant.

In 1927-28 King Ferdinand made a collecting trip to South America and described his experiences in his book "Der König reisst". In 1929 he made an expedition, accompanied by his niece, Princess Victoria, Countess of Solms-Rödelheim, a keen botanist, and his museum curator, Dr. Hans von Boetticher, to Victoria Nyanza and the mountains of equatorial Africa. His account of the expedition, 
with a report on the ornithological observations, compiled by Dr. von Boetticher, was published as a special supplement of the Journal für Ornithologie in 1930. He was a regular attendant of the meetings of the Deutsche Ornithologische Gesellschaft which were held each year in various parts of Germany and took part in all the ornithological excursions, however arduous. In 1934 he attended the International Ornithological Congress at Oxford, including the visit to the bird islands off the Pembrokeshire coast. His enthusiasm and activity were such that even at the age of seventy-six, in 1937, he was considering the possibility of a trip by aeroplane and motor-car from Cairo to the Cape in order to study the bird-life throughout Africa.

He was a brilliant linguist, and in fact it was difficult to discover how many languages he did know, for he would turn with bewildering speed and facility from French, German, English, Bulgarian to Portuguese. His dominating personality, astuteness as a politician and the unpopular role he took in the destinies of Europe have always been emphasized; but his love of beautiful things, his great generosity to the cause of science and to his friends, his delightful sense of humour and a surprising simplicity are sides of his character which have generally been missed.

Phyllis BarcLay-SMITH

WE regret to announce the following deaths:

Peter A. Bungart, for nearly twenty-five years associated with the Department of Geology and Palæontology of the Cleveland Museum of Natural History, who was a distinguished collector and preparator of fossil fish, on July 30, aged seventy-two.

Prof. Alexandr Orlov, professor of petrography and chemical mineralogy at the Charles University of Prague, known for work on the origin and occurrence of groups of ore-bearing rocks and soils, the metamorphosis of limestones and dolomites and especially for his petrographic studies of Czech garnet deposits, aged forty-nine.

Prof. D. A. Welsh, emeritus professor of pathology in the University of Sydney, where he held the chair from 1902 until 1936, on May 13, aged eighty-two.

\section{NEWS and VIEWS}

\section{Botany at Cambridge : \\ Prof. F. T. Brooks, C.B.E., F.R.S.}

ON September 30 Prof. F. T. Brooks retired from the professorship of botany in the University of Cambridge, which he has held since 1936. When he succeeded Sir Albert Seward he became head of a large and well-organised department, which continued to expand and prosper under his direction in spite of the difficulties and restrictions of the war years. At the present time, accommodation in the Botany School is strained to its utmost by everincreasing numbers of research students, and investigations are being made in all the main fields of botanical science, while the number of undergraduate students is well maintained. During his tenure of the chair, Prof. Brooks has continued his researches in plant pathology, and during his career he has been responsible for the training of a large number of mycologists and plant pathologists who now hold important posts in many parts of the world. His wise guidance and administrative ability have been freely extended to the University Botanic Garden; he has acted as chairman of its executive committee and as secretary of the managers of the Cory Trust. His work has extended beyond the University; he was for five years an active member of the Agricultural Research Council and has been one of the general secretaries of the British Association for the Advancement of Science. He will continue to live in Cambridge and to carry on his researches in the Botany School.

\section{Prof. G. E. Briggs, F.R.S.}

Prof. G. E. Briggs will succeed Prof. Brooks as professor of botany. He will be the ninth holder of the chair, which was founded in 1724, and the first plant physiologist to be appointed to it. His researches on photosynthesis and growth have brought him a world-wide reputation as a clever experimenter and a critical and original thinker. A pupil of F. F.
Blackman, he has been head of the Sub-department of Plant Physiology in the Botany School since 1937, and was raised to the rank of professor in 1946. He is a man of wide interests, distinguished as a teacher, and he has had considerable administrative experience in the University and as a fellow and officer of St. John's College.

\section{Solar Eclipse of November I: British Expedition to Mombasa}

A SMALI expedition from the Royal Observatory, Greenwich, under Dr. R. d'E. Atkinson, is proceeding to Mombasa to observe the eclipse of the sun on November 1 ; the purpose is to try out a method of correcting the moon's place from observations on the thin crescent of the sun seen from a station where the eclipse just fails to be total. Measurements of the position-angle of the line of cusps, as a function of the time, can give corrections to the differential co-ordinates of sun and moon which are independent of any assumption about their apparent radii, and independent also of irradiation if the sky is uniform. If a large number of such measures is made, the effects of irregularities of the moon's limb also cancel out to a considerable extent. In the neighbourhood of Mombasa, where the eclipse is nearly 98 per cent total, the position-angle swings round through about $70^{\circ}$ in $2 \frac{1}{2}$ minutes; it is hoped to obtain 3,000 timed pictures on $35-\mathrm{mm}$. film in this interval. The camera will be stationary, and the trail of successive images produced by the sun's diurnal motion will give the zero of position-angles. An ordinary small visual telescope-lens, stopped down to about $f / 40$, is being used, in conjunction with a green filter and exposure times of 1/1,000 sec. Special time-signals will be sent from Rugby, and these will be recorded, together with the instants of the shutter-openings, on tapechronographs which have been made at Abinger. The accuracy of the results will be limited by uncertainties about the contour of the moon's limb; 